\title{
Círculo de Bakhtin: \\ uma Análise Dialógica de Discurso
}

\author{
Bakhtin Circle: a Dialogical Analysis of Discourse
}

\author{
Luciane de Paula \\ Universidade Estadual Paulista
}

Resumo

Este artigo propõe pensar um lugar epistemológico para os estudos do Círculo de Bakhtin e reflete sobre as perspectivas de abordagens brasileiras. Ele reflete, de maneira panorâmica, acerca das questões de produção, circulação e recepção das obras do Círculo russo, a fim de compreender porque, no Brasil, é possível se falar em Análise Dialógica de Discurso (ADD), filiando a denominada filosofia dialógica da linguagem como uma teoria analítica calcada no trânsito entre a linguística e a translinguística. Para isso, centra-se, especificamente, em noções como diálogo, signo ideológico, sujeito e exotopia. A hipótese defendida é a de que, diferentemente de outras Análises de Discursos, o método teórico-analítico do Círculo é o dialógico. Essa é a peculiaridade de sua proposta.

Palavras-chave

Discurso, Círculo de Bakhtin, Brasil.

\section{Abstract}

This article proposes a reflection on a place for epistemological studies about the Bakhtin Circle, as well as it also reflects on the perspectives of Brazilian approaches to that. It also sheds light to the issues concerning the production, the circulation and the reception of works of the Russian Circle in order to understand why, in Brazil, we can speak of Dialogic Discourse Analysis (DDA), affiliating the so-called dialogical 
philosophy of language to an analytical theory, grounded in the relation between linguistics and cross-linguistics. In order to do that, this paper focuses on the notions of dialogue, ideological sign, subject and exotopia. The hypothesis put forward is that, unlike other Analyzes of Discourses, the theoretical-analytical method of the Circle is dialogical. This is the peculiarity of its proposal.

\section{Palavras-chave}

Discourse, Bakhtin Circle, Brazil. 


\section{Introdução}

A Análise de Discurso (AD), no Brasil é, na verdade, as Análises de Discursos (ADs), no plural, dada a diversidade de influências e amplitude de abordagens aqui desenvolvidas. Como já dissemos (PAULA, L. de; STAFUZZA, G, 2010a), essas ADs surgiram tanto das reflexões em salas de aula - onde podemos vislumbrar a condição de produção de pesquisas acadêmicas -, como das conversas e debates com professores universitários brasileiros e estrangeiros (franceses, ingleses, norte-americanos, canadenses, italianos, espanhóis, latino-americanos, alemães, russos, entre outros), também analistas de discursos, que percebem esse diferencial nas pesquisas brasileiras na área. Aqui, pensamos de maneira ampla e, de certa forma, dialógica, pois colocamos em embate as várias perspectivas (AD francesa; ACD - Análise Crítica do Discurso; ADD - Análise Dialógica do Discurso; as semióticas - inglesa e norte-americana, francesa e russa; bem como as teorias enunciativas - de Benveniste aos contemporâneos), dando-lhes um tom identitário (uma cara) brasileiro(a). Por isso, podemos falar em análises de discursos, no plural. Pensar no quadro dos estudos discursivos no Brasil, ainda de maneira au passant (dado o espaço de um artigo), com ênfase na ADD, é a nossa proposta.

Tendo como critério o percurso de constituição das ADs brasileiras, pensamos no papel da filosofia da linguagem do Círculo de Bakhtin, instituída como uma das análises de discursos produzidas em nosso país e refletir sobre esse papel do Círculo russo como ADD é o intuito deste artigo.

A nossa proposta é, a partir do olhar dialógico de uma pesquisadora brasileira, refletir sobre algumas das diferenciações das ADs feitas no Brasil, uma vez que países diferentes, com histórias, culturas e valores distintos, para terem sua identidade teórico-analítica assegurada, buscam caminhos divergentes do saber. Assim, por exemplo, como já dissemos (PAULA, L. de; STAFUZZA, G, 2010a), claro que as Análises de Discursos do Brasil ou Brasileiras dialogam com a $\mathrm{AD}$ francesa, a $\mathrm{ACD}$, a semiologia e a Filosofia da Linguagem, mas já possuem uma identidade teórico-analítica, ainda que utilizem os teóricos fundadores como 
suportes das pesquisas, devido à história de cada país e é essa a riqueza das ADs produzidas e pensadas no Brasil.

O diálogo com teóricos diversos (franceses, ingleses e norte-americanos, alemães, canadenses, italianos, hispânicos, latinos, russos e brasileiros, entre outros) é a garantia de um trabalho sério e fértil que constitui as identidades de ADs feitas no Brasil, uma vez que fortifica um terreno já propício para as pesquisas da área, assim como o seu constante crescimento, como vimos e vemos acontecer, mais especificamente, dos anos 90 do século 20 até hoje (mais de 10 anos do século 21). Todavia, por mais que o diálogo entre abordagens seja enriquecedor, ele pede que sejamos cuidadosos e respeitemos as peculiaridades de cada perspectiva, uma vez que devemos, ao mesmo tempo, considerar suas especificidades ao aproximar e distanciar concepções, a pedido dos corpora de análise - sem jamais nos esquecermos que é o objeto que solicita determinada abordagem conceitual. Afinal, a teoria não deve ser usada como camisa de força que leve a leituras analíticas equivocadas porque forçadas ou porque o analista possui empatia por ela.

Pensamos no diálogo das Análises de Discursos com outras teorias, de diversas áreas, mas privilegiamos a Linguística (o estruturalismo), bem como as suas teorias fundadoras (o marxismo, a psicanálise e o formalismo russo).

Se, por um lado, o diálogo profícuo entre teóricos de diferentes áreas permite às ADs trazer para a linguística uma nova preocupação - abarcar as questões relacionadas à enunciação; por outro, marca uma ruptura com essa mesma área científica do saber, por conceber a história como elemento constituinte do discurso, o que implica dizer que os valores tão renegados pelo chamado estruturalismo de raiz saussureana (o referente extralinguístico - os valores sócio-históricos) passassem a integrar novamente as preocupações investigadas pelos estudos da linguagem (o signo ideológico).

Com isso, a historicidade abandonada pelos estudos linguísticos que dominaram o século 20 , volta à cena com força total, em comunhão com a abordagem sincrônica da linguagem, encarada como composta não por signos linguísticos, mas por signos ideológicos. Num primeiro momento, essa mudança faz com que os linguistas mais ortodoxos excluam os analistas de discursos do campo epistemológico da linguística e diferenciem linguística de AD. Hoje, sabemos ser essa separação absurda, uma vez que o discurso é estruturado linguisticamente e, ao mesmo tempo, só faz e constrói sentido(s) em movimento, no jogo enunciativo, linguístico e translinguístico, como diria Bakhtin. ${ }^{1}$ 


\section{Panorama da produção do Círculo de Bakhtin}

Como já dissemos (PAULA, L. de; STAFUZZA, G, 2010b), Bakhtin já foi denominado teórico da literatura, linguista, filósofo da linguagem, historiador da cultura, entre outras designações. Viveu despercebido em seu meio intelectual acadêmico, no anonimato de sua própria escrita - resistindo à ditadura de Stálin, às fissuras da Revolução Russa, ao exílio no Cazaquistão, à osteomielite, à massificação da cultura do Estado soviético, à difícil sobrevivência à pobreza, sempre motivado por seus escritos inacabáveis e inacabados. Talvez, por isso, diversos especialistas o considerem uma das mais inexplicáveis personalidades das ciências humanas do século 20.

O Círculo de Bakhtin situa-se no contexto da episteme soviética, especialmente nas décadas de 20 e 30 do século 20. Inicialmente, não podemos falar do Círculo sem mencionar a importância da amizade entre seus membros (Bakhtin, Volochinov e Medvedev, entre outros não menos importantes) e seus escritos teórico-filosóficos, às vezes construídos a mais de duas mãos e, alguns, por meio de trocas de identidades sob pseudônimos, como forma de resistência à visão totalitária do stalinismo.

A noção de "ideológico" ou de "signo ideológico" em uma relação já de diálogo com o marxismo (explicitada mais especificamente por Medvedev e Volochinov) é definida na obra Marxismo e filosofia da linguagem (1929) em função da potencialidade de refração de todo fenômeno social-ideológico, ou seja, é o modo de transpor a realidade objetiva conveniente à consciência humana. Nesse sentido, a noção de signo ideológico demonstra a tese do Círculo de Bakhtin sobre o caráter essencialmente material de todo acontecimento dessa ordem.

A afirmação que abre o livro de Volochinov/Bakhtin (Marxismo e filosofia da linguagem) propõe que a ideologia é expressa via material semiótico e tudo que é expresso ou possível de ser expresso, possui um valor ideológico: os objetos materiais apresentam-se dispostos entre os fenômenos ideológicos segundo o critério de sua realização material.

A obra de Bakhtin aparece no cenário acadêmico internacional na década de 80 do século 20, graças aos esforços de Kristeva e Todorov em divulgar o pensamento do filósofo russo sobre literatura. Authier-Revuz cuidou da divulgação na área da linguística quando teorizou sobre as noções de "heterogeneidade mostrada" e "heterogeneidade constituída", em seu texto de 1982, elaborando uma extensão teórica do pensamento bakhtiniano no que diz respeito à evidência do outro no discurso. 
No Brasil, a obra Marxismo e filosofia da linguagem, de 1929, aparece traduzida para o português em 1981, mas somente no final dos anos 80 , início dos anos 90, é que Bakhtin começa a ser lido e discutido mais fortemente na e pela academia, adentrando inclusive nos currículos institucionais: a Pedagogia, já encantada pelas recentes traduções de Vigotski, encontra em Bakhtin um sério interlocutor para a recente redemocratização da época e os debates educacionais - sem adentrarmos nas especificidades sobre a apropriação da área sobre os conceitos de gêneros do discurso e interação verbal; as Ciências Sociais encontra um leitor especial do marxismo que vivenciou a massificação da censura em vida e obra; a História o aprecia tanto pela mesma questão das Ciências Sociais como também o toma em suas linhas de pesquisa que refletem sobre questões de cultura e sociedade. Um exemplo dessa questão está nos entornos da reflexão sobre o humanismo e as humanidades contidos nas obras.

Em 1929, Bakhtin escreve seu livro Problemas da poética de Dostoievski, reeditado em 1963 e publicado em 1965. Nessa obra, Bakhtin trata da tese do romance polifônico, definindo Dostoievski como o romancista (a partir do embate entre as obras de Dostoievski e Tolstoi) criador do "romance polifônico", em que diversas vozes ideológicas contraditórias coexistem com o próprio narrador.

Outra obra de estudos literários bakhtinianos é A Cultura Popular na Idade Média e no Renascimento: o contexto de François Rabelais, produto de uma corajosa tese escrita em 1940 e defendida em 1951 que (após intermináveis discussões da banca examinadora), segundo a academia, "não foi suficiente" para dar a Bakhtin o título de doutor. Nessa obra, o estudioso elaborou a concepção de carnavalização, tendo como esteio a obra de Rabelais. Para Bakhtin, o processo de carnavalização representa um dos eixos da cultura popular, que inclui tanto a inversão hierárquica dos valores pelo poder demolidor do riso quanto o ponto de contato (e de conflito) das diversas linguagens sociais.

Já Questões de literatura e estética é publicado em 1975, sendo uma obra que reúne textos dos anos 30 que se debruçam sobre as questões de autoria, estilo e sobre o herói. Trata-se de uma coletânea que se centra na teoria do romance. Enfim, essas três publicações deram a Bakhtin o status de um respeitável teórico da literatura, legitimando o lugar do autor na teoria literária moderna.

Para uma Filosofia do Ato Responsável, segundo vários especialistas, deve ter sido escrito entre os anos de 1920 e 1924. Um de seus primeiros textos, extremamente filosófico, dado o diálogo profícuo com os neo-kantistas e o desenvolvimento das noções filosóficas de ética, responsabilidade e responsividade. 
Em O Método Formal nos Estudos Literários, de Medvedev, toda a discussão acerca de um método sociológico da linguagem, embrionário em "Discurso na vida e discurso na arte" é desenvolvido, com especial ênfase na concepção de gêneros discursivos - que aparece, sintetizada, num capítulo de Estética da criação verbal, de Bakhtin, anos depois.

Freudismo, de Volochinov, publicado em 1927, apresenta um debate acerca dos pressupostos da teoria freudiana retomada a partir de uma teoria da linguagem.

As edições dos textos do Círculo possuem divergências importantes (como o caso de, no Freudismo, a edição brasileira não contemplar o "Discurso na vida e Discurso na arte" - há uma tradução acadêmica desse texto feita por Faraco e publicada num site inglês, separadamente do Freudismo - ainda que, em outras edições, como a inglesa, esse texto se encontre no final do livro, como sua parte integrante), dadas às questões de direitos autorais e algumas traduções serem feitas diretamente do russo e outras, a partir de outras línguas (tradução da tradução, o que diferencia a organização dos textos e, com isso, a compreensão da obra dos filósofos russos. Um exemplo é, além de Freudismo, o caso de Estética da Criação Verbal. No Brasil, há duas traduções do livro: uma, do francês; e outra, do russo, publicadas, ambas, pela mesma editora. Elas, além de apresentarem questões próprias de tradução, apresentam uma distribuição diferente dos itens do livro - caso de "Gêneros do Discurso", que em cada publicação encontra-se disposto num local diferente).

Como já dissemos (PAULA, L. de; STAFUZZA, G, 2010b), dado o conhecimento esparso da obra do Círculo, aos poucos ao alcance de todos, vários "Bakhtins" surgem e se consolidam em países e culturas de tradições distintas. Assim, o Bakhtin dos países francófonos não é o mesmo Bakhtin anglo-saxão e estes, por sua vez, também se diferem dos Bakhtins hispânicos, italiano e latinos. Dizer isso significa afirmar que, por um lado, ao mesmo tempo que existe uma unicidade nos escritos do Círculo; por outro, há também muitas leituras desses escritos nos diversos países onde foram traduzidos, o que justifica pensarmos na leitura que o Brasil faz das obras do Círculo como um tipo de AD, ou o que Beth Brait denomina Análise Dialógica do Discurso (ADD).

Perante o excesso de documentos emergidos no meio intelectual quase que subitamente, é natural que ocorressem equívocos de interpretação, pois seria necessário tempo para que toda a obra do Círculo fosse conhecida em sua unidade arquitetônica - o que acontece somente no início deste século. Se levarmos em consideração o aparecimento de Bakhtin no Ocidente em total domínio das con- 
cepções imanentes da linguagem, entenderemos o porquê de somente agora nos voltarmos para os seus escritos com profundidade: na Linguística, Saussure e o estruturalismo imperavam; após ele, Chomsky e o gerativismo ocupavam todos os espaços - no entremeio, ouvimos os diálogos de Bakhtin (ainda que sussurrados) com a metafísica, tendo o neo-kantismo e a fenomenologia como interlocutores privilegiados do autor; na teoria literária, o estruturalismo e o formalismo já organizavam a literatura com métodos próprios: enquanto o estruturalista pensava a obra literária enquanto uma possível realização de uma estrutura abstrata geral, o formalista (por fazer parte também de uma tradição estruturalista) considerava a literatura como um sistema regido por leis próprias, fechada em si mesma. Dessa forma, as análises estruturalistas da literatura não relacionam o texto com a consciência criadora do autor, bem como com a sua inscrição sóciohistórica e seu projeto enunciativo. Ao contrário, as abordagens estruturalistas pretendem apreender o texto / enunciado em sua "imanência".

No cenário da terceira época da Análise do Discurso francesa (década de 80, momento em que Pêcheux repensa sua teoria) é que os escritos de Authier-Revuz, os trabalhos de Julia Kristeva e a famosa biografia Mikhail Bakhtin, de Katerina Clark e Michael Holquist lançam os primeiros olhares mais aguçados sobre a teoria, os escritos, a vida e a obra de Bakhtin e Pêcheux admite a contribuição teórica do Círculo para os estudos discursivos. Assim, Bakhtin começa a ser considerado, no campo das ciências humanas, leitura imprescindível no meio intelectual acadêmico e a produção de trabalhos que envolvem conceitos bakhtinianos começa a ter suas extensões teóricas por profissionais das mais diversas áreas, já sendo observados projetos que trazem Bakhtin em seu escopo fora das ciências humanas.

O interesse sobre a obra de Bakhtin e pensar em suas relações teóricas como também em se debater sobre a obra e o pensamento filosófico do Círculo tem sido crescente, como já dissemos (PAULA, L. de; STAFUZZA, G, 2011). Existem, hoje, variados eventos científico-acadêmicos - nacionais e internacionais - de ordem multidisciplinar que trazem, como mote, o estudo de Bakhtin e sua obra. Há ainda o crescimento de grupos de pesquisas institucionais registrados no $\mathrm{CNPq}$ que trazem como foco de trabalho e pesquisa o Círculo de Bakhtin. Interesse também em publicar obras que tratem de temáticas bakhtinianas e que se propõem a refletir, com autores brasileiros e estrangeiros renomados, estudiosos do Círculo de Bakhtin, sobre o complexo escopo de seus estudos, o que se apresenta como possibilidade de contribuir com as pesquisas bakhtinianas no cenário de pesquisas acadêmicas no Brasil e também como forma de legitimar o Círculo enquanto grupo pensador da linguagem. 


\section{Três momentos de recepção: idealização, demonização e interação}

Podemos, em linhas gerais, dizer que a recepção das obras do Círculo de Bakhtin passou por três momentos. Ao menos, vivenciamos o terceiro. Denominamos esses momentos de ideal, demoníaco e interativo, tendo como critério norteador a questão da autoria dos textos. Afinal,

Há cerca de vinte anos, considerávamos que não era necessário apresentar Bakhtin, porque já na década de 1980 numerosos trabalhos em linguística faziam referência às proposições teóricas daquele que desde 1929 propunha o estudo da fala e da enunciação no quadro de uma nova concepção da filosofia da linguagem. Não avaliávamos que havia muito a ser descoberto sobre os escritos dele e do chamado Círculo, sobre o contexto histórico e intelectual onde produziram a obra, nem sobre a reviravolta a que assistimos atualmente sobre a questão da autoria. (CUNHA, 2011, p. 117)

Isso ocorreu porque, no início da recepção das obras do Círculo, tudo se concentrava no nome de Bakhtin e, por esse motivo, para alguns, ele se tornou um ícone dos membros do Círculo, ainda que, para outros, ele apenas nomeie a produção dialógica de todos, sem apagar as peculiaridades autorais de cada um.

Podemos citar alguns nomes que se vinculam aos momentos por nós há pouco mencionados da recepção do Círculo, a título de conhecimento, ainda que superficial, da constituição da ADD por meio da recepção de sua obra.

Num primeiro momento de recepção da obra do Círculo, destacam-se Clark e Holquist e, principalmente, Todorov por, de certa forma, idealizarem Bakhtin, divulgando seu nome por toda a Europa - em especial, nos países francófonos. Segundo o prefácio escrito por Todorov na versão brasileira de Estética da Criação verbal (1981, p. 7), Bakhtin é descrito como "uma das figuras mais fascinantes e enigmáticas da cultura européia de meados do século 20", o que lhe dá um peso dimensionado e, para certa parcela da crítica, exagerado, pois apaga as peculiaridades e a importância dos demais membros do Círculo, em especial, Medvedev e Volochinov, como afirma, por exemplo, Sériot.

Num segundo momento, chamado por nós de demonização ao nome de Bakhtin (em contrapartida a uma espécie de endeusamento inicial), alguns teóricos, como Shneider, Sériot, Bronckart e Botta, voltaram-se de maneira minuciosa à análise das obras do Círculo, a fim de buscar a identidade autoral de alguns dos 
membros - especialmente, Volochinov e Medvedev, bem como passaram a estudar detalhadamente a obra até então chamada ou conhecida (como ficou e é denominada até hoje) de Bakhtin, até que a famosa citação de Cassirer sem menção alguma ao autor original (seja em forma de destaque - itálico, aspas - ou referência direta) foi encontrada num dos livros de Bakhtin e isso serviu para, na Europa, um grupo de intelectuais que, a nosso ver, não entende o método dialético-dialógico da filosofia da linguagem do Círculo e ainda desconsidera o contexto de produção das obras (a Rússia com seu quadro político-econônico e sociocultural conturbado dos anos 20 aos 70 - momento de produção dos escritos do Círculo) acusar Bakhtin (e apenas ele, seja visto como ícone dos demais membros seja de maneira individual) de plágio e isso gerou polêmica, divide opiniões e rende pesquisas até hoje, em que já temos acesso a parte dos manuscritos do Círculo, encontrados em seus arquivos, em estudo por grupos de intelectuais russos, alemães, franceses e ingleses.

Num terceiro momento, vivido por nós na contemporaneidade, de certa maneira, sem desprezar a história e a importância de duas décadas de estudos, experimentamos uma outra e nova recepção, pois conseguimos identificar as autorias, ter acesso a alguns textos que ainda não tinham sido prublicados no Brasil e também pensar na cronologia da escrita da obra, o que muito auxilia na compreensão das concepções teórico-analíticas do Círculo, visto como um todo, de maneira dialógica, por isso, o nome atribuído por nós a essa fase - se assim podemos chamar este momento - de interativo.

Afinal, ao mesmo tempo em que nos preocupamos com o método de produção, circulação e recepção conturbado dos escritos do Círculo, encarandoos como dialógicos, uma vez que escritos, algumas vezes, a quatro mãos, outras, com pseudônimos e muitas ainda de maneira responsiva, com perspectivas e enfoques diferentes, mas centrados no mesmo enfoque: a questão da linguagem, como defendem Gardner, Morson e Emerson, Vauthier, Ponzio e Petrilli, Zavalla e Bubnova; também identificamos as peculiaridades autorais, especialmente de Bakhtin, Medvedev e Volochinov, o que nos auxilia a entender as perspectivas e os desenvolvimentos teóricos de toda a obra do Círculo, como fazem os ingleses (como Craig Brandist, em Shefield, por exemplo), Galin Tihanov, entre outros. 


\section{O Círculo de Bakhtin como Análise Dialógica do Discurso (ADD)}

Agrupar convergências dentre teóricos de perspectivas distintas sem transformar suas propostas em uma "fôrma" homogênea onde cabe qualquer afirmação é uma tarefa fundamental. Para isso, consideramos também as peculiaridades de seus estudos, para, como afirma Gregolin (2006, p. 34), não "transformá-los em fetiches teóricos", a fim de "enxergar a contribuição de cada um deles num certo momento da construção de um grande projeto teórico que atravessou o século 20 e se estende até os nossos dias", ou seja, as ADs.

Consideramos Bakhtin como ADD exatamente para distingui-lo de outros pensadores de outras perspectivas teóricas (como Pêcheux, Foucault, Maingueneau, Charaudeau, Amossy na AD francesa, por exemplo), sem apagar a singularidade de suas posições teóricas e, calcadas em Gregolin (idem), posicionarmo-nos "contra a homogeneização que, nas palavras de Courtine, 'amalgama, neutraliza e torna indistinguível sob uma etiqueta consensual posições teóricas contraditórias'.”. Conforme salienta Gregolin (2006, p. 47),

(...) em relação à circulação das idéias de Bakhtin, promove-se uma 'desmarxização' de suas formulações e a redução de suas propostas a conceitos operatórios desligados das motivações filosóficas que os engendram. Essa 'desmarxização' (que é, fundamentalmente, uma 'des-historicização') acaba produzindo como efeito o apagamento das polêmicas estabelecidas entre Bakhtin e outros 'marxistas' (como os althusserianos e os foucaultianos).

Pensar em AD francesa, por exemplo, significa falar em Pêcheux e este, embora possua convergências com o pensamento bakhtiniano no final ("terceira época" - In:GADET; HAK, 1995) de sua produção, mas também, principalmente no início de suas formulações teóricas, possui divergências que devem ser explicitadas. Uma delas, segundo Gregolin, é, por exemplo, a leitura marxista de Pêcheux e de Bakhtin. A diferença de leitura da obra marxista leva ao que Gregolin (2006, p. 39) denomina "uma crise no interior da 'análise do discurso francesa', uma divisão entre aqueles que Pêcheux classifica como linguistas marxistas e aqueles rotulados como os sociologistas.".

Para Pêcheux, a produção de sentido não pode ser pensada nas esferas interindividuais ou ser tomada como interação entre grupos. Assim, a divisão proposta por Pêcheux leva ao que Gregolin (2006, p. 39-40) chama de "uma luta teórica determinada pelas diferentes posições dos intelectuais franceses, nos anos 
1970, no interior do Partido Comunista Francês". Explica Gregolin (idem) que "Aliando-se à vertente dos linguistas marxistas, Pêcheux critica os 'sociologistas' que desenvolvem uma 'sociolinguística materialista' centrada nas ideias de interação e dialogismo", conceitos centrais em Bakhtin.

No entanto, a partir de 1978, de acordo com Gregolin (2006, p. 45-46), "Pêcheux inicia um período de autocríticas que irá deslocá-lo, teórica e politicamente, das posições dogmáticas da 'primeira época'.". A partir desse momento histórico, a discussão da articulação entre discurso e história torna-se proeminente. Essa discussão traz com ela, segundo Gregolin (idem), "ampla reformulação" teórica da e na análise do discurso. Essa nova "época" da AD, conforme Gregolin (ibidem), "integra a noção bakhtiniana de heterogeneidade" (trazida para a França por Kristeva e também estudada por Authier-Revuz).

Assim, considerar Bakhtin como analista discursivo, para os mais ortodoxos, desloca seus trabalhos de sua episteme. Há também estudiosos que defenderão e outros que questionarão se Bakhtin pode ser considerado teórico e se ele possui uma proposta teórica formalizada. Para explicar nossa adoção aos conceitos, muitas vezes considerados filosóficos, do Círculo de Bakhtin, calcamo-nos em Brait (2006, p. 9-10), que afirma que

Ninguém, em sã consciência, poderia dizer que Bakhtin tenha proposto formalmente uma teoria e / ou análise do discurso (...). Entretanto, também não se pode negar que o pensamento bakhtiniano representa, hoje, uma das maiores contribuições para os estudos da linguagem, observada tanto em suas manifestações artísticas como na diversidade de sua riqueza cotidiana. Por essa razão, mesmo consciente de que Bakhtin, Volochinov, Medvedev e outros participantes do que atualmente se denomina Círculo de Bakhtin jamais tenham postulado um conjunto de preceitos sistematicamente organizados para funcionar como perspectiva teórico-analítica fechada" ainda que "o conjunto das obras do Círculo motivou o nascimento de uma análise / teoria dialógica do discurso (...).

Brait (2006, p. 10) denomina "teoria dialógica do discurso", sem uma definição fechada, o que seria uma contradição com o próprio conceito teórico,

(...) a indissolúvel relação existente entre língua, linguagens, história e sujeitos que instaura os estudos da linguagem como lugares de produção de conhecimento de forma comprometida, responsável, e não apenas como procedimento submetido a teorias e metodologias do- 
minantes em determinadas épocas". Esse embasamento constitutivo diz respeito a uma concepção de linguagem, de construção e produção de sentidos necessariamente apoiadas nas relações discursivas empreendidas por sujeitos historicamente situados.

Brait concebe os estudos da linguagem empreendidos pelo Círculo de Bakhtin como formulações em que o conhecimento é concebido de forma viva, produzido e recebido em contextos históricos e culturais específicos. Sob esse prisma, a compreensão da conceituação de translinguística, tal qual sugerida por Bakhtin (1981), é fundamental para entender a concepção de Brait acerca dos estudos bakhtinianos como teoria / análise do discurso - ADD. Segundo Brait (2006, p. 10), "No início do capítulo 'O discurso em Dostoiévski', encontra-se o primeiro momento em que uma 'análise / teoria dialógica do discurso' é proposta”. No capítulo citado por Brait, Bakhtin (1981, p. 181) afirma que

Intitulamos este capítulo 'O discurso em Dostoiévski' porque temos em vista o discurso, ou seja, a língua em sua integridade concreta e viva e não a língua como objeto específico da Lingüística, obtido por meio de uma abstração absolutamente legítima e necessária de alguns aspectos da vida concreta do discurso. Mas são justamente esses aspectos, abstraídos pela Lingüística, os que têm importância primordial para os nossos fins. Por estes motivos, as nossas análises subseqüentes não são lingüísticas no sentido rigoroso do termo. Podem ser situadas na Metalingüística, subentendendo-a como um estudo - ainda não constituído em disciplinas particulares definidas - daqueles aspectos da vida do discurso que ultrapassam - de modo absolutamente legítimo - os limites da Lingüística. As pesquisas metalingüísticas, evidentemente, não podem ignorar a Lingüística e devem aplicar os seus resultados. A Lingüística e a Metalingüística estudam o mesmo fenômeno concreto, muito complexo e multifacético - o discurso, mas estudam sob diferentes ângulos de visão. Devem completar-se mutuamente e não fundir-se.

Adiante, Bakhtin (1981, p. 182) substitui o termo discurso, objeto pertencente tanto à linguística quanto à translinguística, como assinala Brait (2006, p. 12), por "relações dialógicas". Com isso, Bakhtin, sem se esquecer que a preocupação da translinguística é também uma preocupação linguística, atribui uma “dimensão extralinguística" a ela (translinguística): 
Assim, as relações dialógicas são extralingüísticas. Ao mesmo tempo, porém, não podem ser separadas do campo do discurso, ou seja, da língua enquanto fenômeno integral concreto. A linguagem só vive na comunicação dialógica daqueles que a usam. É precisamente essa comunicação dialógica que constitui o verdadeiro campo da vida da linguagem. Toda a vida da linguagem, seja qual for o seu campo de emprego (a linguagem cotidiana, a prática, a científica, a artística, etc.), está impregnada de relações dialógicas. Mas a Lingüística estuda a linguagem propriamente dita com sua lógica específica na sua generalidade, como algo que torna possível a comunicação dialógica, pois ela abstrai conseqüentemente as relações propriamente dialógicas. Essas relações se situam no campo do discurso, pois este é por natureza dialógico e, por isto, tais relações devem ser estudadas pela Metalingüística, que ultrapassa os limites da Lingüística e possui objeto autônomo e metas próprias.

Essa citação traz à tona uma das características de abordagem dos estudos da linguagem do Círculo de Bakhtin: a ADD não pode se centrar apenas externa nem, tampouco, apenas internamente, pois, segundo Brait (2006, p. 13),

Excluir um dos pólos é destruir o ponto de vista dialógico, proposto e explicitado pela teoria e pela análise, e dado como constitutivo da linguagem. É a bivocalidade de 'diálogo', situado no objeto e na maneira de enfrentá-lo, que caracteriza a novidade da Metalingüística.

Dessa forma, a abordagem de estudo bakhtiniana de linguagem, sua ADD, considera as particularidades discursivas que apontam para contextos mais amplos, para um extralinguístico incluído no linguístico. Assim, segundo Brait (2006, p. 13), o trabalho metodológico, analítico e interpretativo ocorre por meio da herança advinda da linguística de

(...) esmiuçar campos semânticos, descrever e analisar micro e macroorganizações sintáticas, reconhecer, recuperar e interpretar marcas e articulações enunciativas que caracterizam o(s) discurso(s) e indicam sua heterogeneidade constitutiva, assim como a dos sujeitos aí instalados. E mais ainda: ultrapassando a necessária análise dessa 'materialidade lingüística', reconhecer o gênero a que pertencem os textos e os gêneros que nele se articulam, descobrir a tradição das atividades em que esses discursos se inserem e, a partir desse diálogo com o objeto de análise, chegar ao inusitado de sua forma de ser dis- 
cursivamente, à sua maneira de participar ativamente de esferas de produção, circulação e recepção, encontrando sua identidade nas relações dialógicas estabelecidas com outros discursos, com outros sujeitos.

Para compreendermos a concepção teórica e analítica sugerida pelos trabalhos do Círculo de Bakhtin, devemos considerar ainda o sujeito. Para essa abordagem dialógica, o sujeito é, sempre, composto a partir e por meio do "outro". Assim, o "outro" é condição sine qua non para a existência do "eu". Entretanto, como afirma Brait (2006, p. 21), "Postular a existência de uma teoria/análise do discurso" em Bakhtin "exige, por assim dizer, uma reconstituição do percurso desse pensamento", o que não conseguimos fazer no espaço de um artigo, mas dizemos que essa tem sido a tarefa a que diversos grupos de pesquisadores e estudiosos sérios, brasileiros e estrangeiros, têm se proposto a percorrer: a registro, a reflexão e a compreensão da constituição e consolidação de uma ADD feita no Brasil.

\section{Considerações porvir}

Em síntese, podemos dizer que, apesar do Círculo de Bakhtin ter produzido seus trabalhos sobre a linguagem desde a segunda década do século 20, os linguistas entraram em contato com esse pensamento no final da década de 70, por meio de Marxismo e Filosofia da Linguagem. Nesse momento, tanto quanto Gregolin, Brait (2006, p. 22) afirma que esse texto aparece como uma espécie de "terceira margem dos estudos da linguagem", por propor a inclusão do sujeito e da história a esses estudos.

A concepção de que todo signo é ideológico advém do fato de que nenhuma ideologia pode aparecer fora dos signos, portanto, nenhum signo está despido de ideologia. O salto proposto ao estudo da linguagem sob essa perspectiva foi o de observá-la em uso, na combinatória das dimensões da langue e da parole, do social / sistêmico e do "individual", conforme Brait (2006, p. 23), "como forma de conhecer o ser humano, suas atividades, sua condição de sujeito múltiplo, sua inserção na história, no social, no cultural pela linguagem, pelas linguagens.".

Contudo, o texto Problemas da poética de Dostoiévski é que traz, com a formulação do conceito de polifonia, uma das mais importantes características de uma teoria / análise dialógica do discurso sugerida por Bakhtin também em outros textos (como ocorre com a formulação dos conceitos de carnaval, cultura 
popular e riso, em A cultura popular na Idade Média e no Renascimento: o contexto de François Rabelais, por exemplo): não utilizar concepções teóricas como "camisas de força", ou seja, nas palavras de Brait (2006, p. 24), "não aplicar conceitos, a fim de compreender um discurso, mas deixar que os discursos revelem sua forma de produzir sentido, a partir do ponto de vista dialógico, num embate". Assim, a abertura teórico-analítica em Bakhtin não significa uma falta de metodologia e / ou de sistematização formal, mas, ao contrário, essa abertura é a própria proposta teórico-analítica, pois, como afirma Amorim (2003, p. 12),

(...) a produção de conhecimento e o texto em que se dá esse conhecimento são uma arena onde se confrontam múltiplos discursos. Por exemplo, entre o discurso do sujeito analisado e conhecido e o discurso do próprio pesquisador que pretende analisar e conhecer, uma vasta gama de significados conflituais e mesmo paradoxais vai emergir. Assumir esse caráter conflitual e problemático das Ciências Humanas implica renunciar a toda ilusão de transparência: tanto do discurso do outro quanto de seu próprio discurso. E é portanto trabalhando a opacidade dos discursos e dos textos, que a pesquisa contemporânea pode fazer da diversidade um elemento constituinte do pensamento e não um aspecto secundário.

Em outras palavras, o que procuramos construir neste artigo não é pensar a filosofia bakhtiniana como uma teoria / análise fechada, pronta e acabada, mas, como afirma Brait (2006, p. 29), com relação às contribuições bakhtinianas para uma teoria / análise dialógica do discurso, “(...) um corpo de conceitos, noções e categorias que especificam a postura dialógica diante do corpus discursivo, da metodologia e do pesquisador.". Afinal, conforme Brait (idem), "A pertinência de uma perspectiva dialógica se dá pela análise das especificidades discursivas constitutivas de situações em que a linguagem e determinadas atividades se interpenetram e interdefinem, e do compromisso ético do pesquisador com o objeto, que, dessa perspectiva, é um sujeito histórico.”.

As Ciências Humanas são entendidas pelo Círculo de Bakhtin como ciências do texto / discurso, pois o que há de fundamentalmente humano no homem é o fato de ser um sujeito produtor de textos (orais e escritos, verbais, não verbais e sincréticos). Assim, pesquisador e sujeitos pesquisados são, como retratista e sujeito retratado, ambos, produtores de textos / discursos, o que, segundo Amorim (2006, p. 98), “confere às Ciências Humanas um caráter dialógico”. Isso quer dizer, conforme Amorim (idem), que 
Uma primeira consequência disto é que o texto do pesquisador não deve emudecer o texto do pesquisado, deve restituir as condições de enunciação e de circulação que lhe conferem as múltiplas possibilidades de sentido. Mas o texto do pesquisado não pode fazer desaparecer o texto do pesquisador, como se este se eximisse de qualquer afirmação que se distinga do que diz o pesquisado. O fundamental é que a pesquisa não realize nenhum tipo de fusão dos dois pontos de vista, mas que mantenha o caráter de diálogo, revelando sempre as diferenças e a tensão entre elas. Importante ressaltar que esse diálogo não é simétrico e aqui reaparece o conceito de exotopia. O pesquisador deve fazer intervir sua posição exterior: sua problemática, suas teorias, seus valores, seu contexto sócio-histórico, para revelar do sujeito algo que ele mesmo não pode ver.

Numa tradução de Bakhtin (“Les études littéraires aujourd'hui", 1984, p. 348) feita por Amorim (2006), podemos ratificar a importância do conceito de exotopia para a compreensão da dimensão dos estudos culturais:

No âmbito da cultura, a exotopia é o motor mais potente da compreensão. Uma cultura estrangeira não se revela em sua completude e em sua profundidade a não ser através do olhar de uma outra cultura (e ela não se revela nunca em toda sua plenitude, pois outras culturas virão e poderão ver e compreender mais ainda). (...) Face a uma cultura estrangeira, colocamos perguntas novas que ela mesma não se colocava. Procuramos nelas uma resposta a essas questões que sãos as nossas, e a cultura estrangeira nos responde, nos desvelando seus aspectos novos, suas profundidades novas de sentido. Se não colocamos nossas próprias questões, nos desligamos de uma compreensão ativa de tudo que é outro e estrangeiro (trata-se, bem entendido, de questões sérias, verdadeiras).

Nesse sentido, o valor do conceito de exotopia para a pesquisa, segundo Amorim (2006, p. 100), "é confirmado pelo modo como Bakhtin analisa o trabalho de compreensão do texto do outro", que é descrito por Bakhtin (1992, p. 365) a partir de uma dimensão espacial (embora o conceito de exotopia designe uma posição no tempo). Afinal, a exotopia designa uma relação de tensão entre pelo menos dois lugares: o do sujeito que vive e olha de onde vive, e daquele que, de fora da experiência do primeiro, tenta mostrar o que vê do olhar do outro. Em outras palavras, de acordo com Amorim, o papel de pesquisa da ADD inclui a tarefa 
dialógica do pesquisador e do seu outro, uma vez que a função analítica do pesquisador é a de tentar enxergar com os olhos do outro e a de retornar à sua exterioridade para fazer intervir com o seu olhar (de pesquisador) - a sua posição singular sobre e num dado contexto e os valores que afirma sobre aqueles afirmados pelo outro. Método dialógico de pesquisa. Filosofia de vida. Uma Análise Dialógica de Discursos.

\section{Referências}

AMORIM, M. "Cronótopo e exotopia". In: BRAIT, B. (Org.). Bakhtin - outros conceitos-chave. São Paulo: Contexto, 2006.

AMORIM, M. "A contribuição de Mikhail Bakhtin: a tripla articulação ética, estética e epistemológica". In: FREITAS, M. T. et al. Ciências Humanas e pesquisa: leituras de Mikhail Bakhtin. São Paulo: Cortez, 2003.

AMORIM, M. O pesquisador e seu outro: Bakhtin nas Ciências Humanas. São Paulo: Musa, 2001.

BAKHTIN, M. M. (VOLOCHINOV) (1929). Marxismo e filosofia da linguagem. São Paulo: Hucitec, 1992.

BAKHTIN, M. M. Discurso na vida e discurso na arte. Tradução para fins acadêmicos de Carlos Alberto Faraco. Circulação restrita. Mimeo.

BAKHTIN, M. M. (MEDVEDEV). Método Formal nos Estudos Literários. São Paulo: Contexto, 2011.

BAKHTIN, M. M. Problemas da poética de Dostoiévski. Rio de Janeiro: Forense Universitária, 1981.

BAKHTIN. M. M. (1929) Problemas da Poética de Dostoievski. São Paulo: Forense, 1997.

BAKHTIN, M. M. (1920-1974). Estética da Criação Verbal. (Edição traduzida do russo). São Paulo: Martins Fontes, 2003.

BAKHTIN, M. M. (1975). Questões de Literatura e de Estética. São Paulo: UNESP, 1993.

BAKHTIN, M. M. Freudismo. São Paulo: Perspectiva, 2001.

BAKHTIN, M. M. (1920-1924) Para uma filosofia do ato responsável. São Carlos: Pedro \& João Editores, 2010.

BAKHTIN, M. M. Cultura popular na Idade Média e no Renascimento: o contexto de François Rabelais. São Paulo: Martins Fontes, 2003.

BRAIT, B. "Análise e teoria do discurso". In: BRAIT, B. (Org.). Bakhtin- outros conceitos-chave. São Paulo: Contexto, 2006.

BRAIT, B. "Introdução. Alguns pilares da arquitetura bakhtiniana". In: BRAIT, B. (Org.). 
Bakhtin: Conceitos-Chave. São Paulo: Contexto, 2006.

CLARK, K.; HOLQUIST, M. Mikhail Bakhtin. São Paulo: Perspectiva, 1998.

CUNHA, D. "Formas de presença do outro na circulação dos discursos". Bakhtiniana. Revista de Estudos do Discurso. PUC - SP, n.. 5, p. 116-132, 2011. ISSN: 2176-4573.

GADET, F.; HAK, T. Por uma análise automática do discurso. Campinas: Editora da UNICAMP, 1995.

GREGOLIN, M. R. V. "Bakhtin, Foucault, Pêcheux.” In: BRAIT, B. (Org.). Bakhtin outros conceitos-chave. São Paulo: Contexto, 2006.

PAULA, L. de; STAFUZZA, G. (Org.). "Prefácio". Da Análise do Discurso no Brasil à Análise do Discurso do Brasil: três épocas histórico-analíticas. Uberlândia: EDUFU, 2010a.

PAULA, L. de; STAFUZZA, G. (Org.). "Prefácio". Círculo de Bakhtin: teoria inclassificável. Volume 1. Série Bakhtin - Inclassificável. Campinas: Mercado de Letras, 2010b. PAULA, L. de; STAFUZZA, G. (Org.). Círculo de Bakhtin: diálogos (in)possíveis. Volume 2. Série Bakhtin - Inclassificável. Campinas: Mercado de Letras, 2011.

PÊCHEUX, M. "Análise do discurso: três épocas." In: GADET, F.; HAK, T. Por uma análise automática do discurso: uma introdução à obra de Michel Pêcheux. Campinas: UNICAMP, 1995.

PÊCHEUX, M. "Só há causa daquilo que falha ou o inverno político francês: início de uma retificação." In: pinas: UNICAMP, 1997. Semântica e Discurso: uma crítica à afirmação do óbvio. Cam- 
